\title{
Effect of Blood Storage on Complete Biochemistry
}

Monica Verma ${ }^{1 *}$, Kiran Dahiya ${ }^{1}$, Deepika Malik ${ }^{1}$, Sehgal PK ${ }^{1}$, Rama Devi ${ }^{2}$, Abhishek Soni ${ }^{2}$ and Veena Singh Ghalaut ${ }^{1}$

${ }^{1}$ Department of Biochemistry, Pt. B.D. Sharma, University of Health Sciences, Rohtak, Haryana, India

${ }^{2}$ University of Health Sciences, Rohtak, Haryana, India

"Corresponding author: Monica Verma, MBBS, MD (Biochemistry), Senior Resident, Department of Biochemistry, Pt. B.D. Sharma, University of Health Sciences, 236G, Model Town, Rohtak, Haryana-124001, India, Tel: +919813334543; E-mail: monisoni26@gmail.com

Received date: Oct 12, 2015, Accepted date: Dec 28, 2015, Publication date: Dec 31, 2015

Copyright: ( 2015 Verma M, et al. This is an open-access article distributed under the terms of the Creative Commons Attribution License, which permits unrestricted use, distribution, and reproduction in any medium, provided the original author and source are credited.

\begin{abstract}
Background: Prolonged storage of blood leads to alteration in RBCs biochemistry which may lose viability with time.

Aim: This study was planned to observe biochemical changes on stored blood on 19 different analytes.

Material and Methods: The study was conducted on blood donated by 30 healthy volunteer donors. Effect of storage was analyzed at $0,3,7,14$ and 21 days interval. Biochemical parameters were measured using Randox suzuka autoanalyzer and Combiline ISE analyzer.

Results: Significant changes were observed in serum phosphorus, SGOT, serum protein, LDH, pH, serum chloride, ionized calcium, serum sodium, potassium and bicarbonate levels $(p<0.05$ for ionized calcium, serum protein and $p<0.001$ for rest of the parameters). On the other hand there was no impact of storage time on rest of the parameters.

Conclusion: Prolonged contact of plasma with RBCs results in exchange of contents between plasma and red cells which leads to changes in analyte concentrations as well as dilution. RBC stored for a period of time at $4^{\circ} \mathrm{C}$ loose viability. Some may undergo spontaneous hemolysis while in storage; others lose the ability to survive in the recipient's circulation following transfusion. Inspite of storing blood with CPDA, the storage time has a negative impact on the biochemical composition of RBCs. Therefore, it is better to give patients fresh blood with less than 7 days of storage in order to decrease the levels of non-viable red blood cells.
\end{abstract}

Keywords: Hemolysis; Blood; Transfusion

\section{Introduction}

In $4^{\circ} \mathrm{C}$ liquid storage, the biochemical and mechanical properties of red blood cells (RBCs) deteriorate progressively. When blood is stored in blood bank, biochemistry and physical properties of RBCs are altered because of storage conditions. These are referred to as storage lesions. Under normal conditions in the body's circulation, these do not occur as optimum temperature, $\mathrm{pH}$, nutrient concentration and waste product removal are maintained [1].

Hemolysis can produce three sorts of effects: the release of erythrocytic constituents can result in some increased values for serum; there is some dilution, resulting in decreased values; and hemoglobin may interfere directly, e.g. in the colorimetric quantitation of constituents. Caraway reported that erythrocytes contain about 160fold as much lactate dehydrogenase, 67-fold as much acid phenyl phosphatase, 20-fold as much aspartate aminotransferase, and 23-fold as much potassium as does plasma [2]. Visible hemolysis is commonly defined as an extracellular hemoglobin concentration of $0.3 \mathrm{~g} / \mathrm{L}$ (4.65 $\mathrm{mol} / \mathrm{L}$ ), resulting in a detectable pink-to-red hue of serum or plasma with a visible appearance in specimens containing as low as $0.5 \%$ hemolysate [3].
This study was planned to observe biochemical changes on stored blood on 19 different analytes at an interval of $0,3,7,14$ and 21 days.

\section{Material and Methods}

The present research was conducted in Pt B D Sharma PGIMS, Rohtak in collaboration of biochemistry department with blood transfusion department of our institute. $450 \mathrm{ml}$ of blood was drawn from 30 healthy volunteer donors into citrate phosphate dextrose adenine (CPDA-1) anticoagulant $(63 \mathrm{ml})$. Blood was collected with adequate safety precautions to avoid contamination and infection. Blood donors were screened as per regulations of drugs and cosmetics rules, Government of India [4]. All subjects were serologically examined for hepatitis B virus, hepatitis $\mathrm{C}$ virus and HIV before blood donation. Blood bags were carefully stored in a quarantine shelf in the blood bank at $2-4^{\circ} \mathrm{C}$.

Citrate phosphate dextrose adenine solution was developed in 1968 and shown to permit whole-blood storage for 5 weeks [5]. Most blood collection bags (adult) contain $63 \mathrm{ml}$ CPDA anticoagulant which is sufficient to anticoagulate and ensure the viability of blood cells in 450 $\mathrm{ml} \pm 10 \%$ blood for up to $28-35$ days when the blood is stored at $2-8^{\circ} \mathrm{C}$ [6].

A $50 \mathrm{ml}$ blood sample from each blood bag was taken for study purpose and stored in plain bags. Rest of the blood was used for 
Page 2 of 4

transfusion purpose. Effect of storage was analyzed at 0, 3, 7, 14 and 21 days interval by withdrawing $8 \mathrm{ml}$ blood each time from the bag. The sample analyzed on 0 day served as control. Biochemical parameters were measured using Randox suzuka autoanalyzer and Combiline. Alkaline phosphatase (ALP) (IFCC method with aminomethylpropanol buffer), alanine aminotransferase (ALT) (IFCC method without pyridoxal phosphate activation), aspartate aminotransferase (AST) (IFCC method without pyridoxal phosphate activation), creatinine (Jaffe kinetic method), lactate dehydrogenase (LDH) (DGKC method), inorganic phosphorus (UV Molybdate method), urea (urease method), total protein (biuret method), cholesterol (Enzymatic endpoint method), triglycerides (GPO method), HDLcholesterol (Enzymatic method) and uric acid (uricase method) were assayed on an automated clinical chemistry autoanalyzer (Randox suzuka), according to the manufacturer's specifications and using proprietary reagents. Sodium, calcium, chloride, potassium and $\mathrm{pH}$ were measured on Combiline Ion Selective Electrode analyzer by an indirect method using ion-selective electrodes.

Normal ranges of different parameters used in this study are as follows: urea $(10-50 \mathrm{mg} / \mathrm{d} / \mathrm{L})$, creatinine $(0.7-1.3 \mathrm{mg} / \mathrm{dL})$, uric acid (3-7 $\mathrm{mg} / \mathrm{dL})$, phosphorus (2.5-4.5 $\mathrm{mg} / \mathrm{dL})$, ionized calcium (1.1-1.35 $\mathrm{mmol} / \mathrm{L}$ ), AST (upto $40 \mathrm{U} / \mathrm{L}$ ), ALT (upto $40 \mathrm{U} / \mathrm{L}$ ), ALP (30-120 U/L), total proteins $(6-8 \mathrm{~g} / \mathrm{L})$, cholesterol $(130-230 \mathrm{mg} / \mathrm{dL})$, triglycerides (60-160 mg/dL), HDL cholesterol (30-60 mg/dL), blood sugar (70-110 $\mathrm{mg} / \mathrm{dL}), \mathrm{LDH}$ (235-470 U/L), sodium (135-155 mEq/L), potassium (3.5-5.5 $\mathrm{mEq} / \mathrm{L})$, chloride (96-112 $\mathrm{mEq} / \mathrm{L})$ and $\mathrm{pH}(7.38-7.42)$.
Standard statistical methods were used to determine the mean, and standard deviation. Student t-test was used to find the effect of blood storage on its hematochemical parameters. The blood at zero time is considered as a control. All values were quoted as the mean \pm SD. The difference between observations was considered significant at $\mathrm{p}<0.05$. Correlation analysis was used to find the relationship between hematochemical parameters and period of storage.

\section{Results}

Out of 30 donors 25 were males and 5 were females. There ages ranged between $21-40$ years (mean age 24.2 years) with corresponding blood groups of $6 \mathrm{O}^{+}, 15 \mathrm{~B}^{+}, 4 \mathrm{~A}^{+}, 1 \mathrm{AB}^{+}, 1 \mathrm{O}^{-}, 2 \mathrm{~A}^{-}$and $1 \mathrm{~B}^{-}$. The various biochemical parameters analyzed are shown in Table1.

Significant changes were observed in serum phosphorus, AST, serum protein, $\mathrm{LDH}, \mathrm{pH}$, serum chloride, ionized calcium, serum sodium, potassium and bicarbonate levels ( $\mathrm{p}<0.05$ for ionized calcium, serum protein and $\mathrm{p}<0.001$ for rest of the parameters). At the end of $21^{\text {st }}$ day there was $34.91 \%, 94.38 \%, 9.12 \%, 265.59 \%, 25 \%, 522 \%$ increase in serum phosphorus, AST, serum protein, calcium and potassium levels respectively and $4 \%, 2 \%, 9 \%, 79 \%$ decrease in $\mathrm{pH}$, serum chloride, sodium and bicarbonate levels respectively. On the other hand there was no impact of storage time on rest of the parameters.

\begin{tabular}{|c|c|c|c|c|c|c|}
\hline Parameter & $\begin{array}{l}\text { Day } 0 \\
\mathrm{~N}=20\end{array}$ & $\begin{array}{l}\text { Day } 3 \\
\mathrm{~N}=20\end{array}$ & $\begin{array}{l}\text { Day } 7 \\
N=20\end{array}$ & $\begin{array}{l}\text { Day } 14 \\
\mathrm{~N}=20\end{array}$ & $\begin{array}{l}\text { Day } 21 \\
\mathrm{~N}=20\end{array}$ & pvalue \\
\hline UREA (mg/dL) & $24.7 \pm 4.82$ & $23.1 \pm 4.87$ & $25.86 \pm 5.85$ & $23.3 \pm 2.79$ & $23.2 \pm 1.3$ & 0.176 \\
\hline CREATININE (mg/dL) & $1.06 \pm 0.07$ & $1.08 \pm 0.08$ & $1.04 \pm 0.08$ & $1.03 \pm 0.10$ & $1.04 \pm 0.10$ & 0.153 \\
\hline URIC ACID (mg/dL) & $5.22 \pm 0.81$ & $5.39 \pm 0.86$ & $5.29 \pm 0.93$ & $5.1 \pm 1.05$ & $5.1 \pm 1.8$ & 0.747 \\
\hline PHOSPHORUS (mg/dL) & $11.86 \pm 0.62$ & $12.26 \pm 0.86$ & $13.4 \pm 1.15$ & $15.0 \pm 0.76$ & $16.0 \pm 0.88$ & $0.000^{* *}$ \\
\hline AST (mg/dL) & $23.15 \pm 6.25$ & $24.0 \pm 8.61$ & $29.7 \pm 9.32$ & $41.1 \pm 10.36$ & $45 \pm 6.7$ & $0.000^{* *}$ \\
\hline $\mathrm{ALT}(\mathrm{mg} / \mathrm{dL})$ & $41.45 \pm 20.88$ & $41.25 \pm 23.7$ & $37 \pm 22.4$ & $47 \pm 28.36$ & $49 \pm 23.55$ & 0.312 \\
\hline PROTEIN (g/dL) & $6.14 \pm 0.24$ & $6.3 \pm 0.24$ & $6.27 \pm 0.30$ & $6.41 \pm 0.22$ & $6.7 \pm 0.77$ & $0.003^{*}$ \\
\hline TRIGLYCERIDES (mg/dL) & $175.2 \pm 61.63$ & $162.1 \pm 57.32$ & $147.26 \pm 58.7$ & $154 \pm 54.07$ & $152 \pm 16.2$ & 0.449 \\
\hline CHOLESTEROL (mg/dL) & $147.15 \pm 25.47$ & $141.4 \pm 24.72$ & $141.8 \pm 23$ & $137.3 \pm 23.2$ & $135 \pm 14.7$ & 0.599 \\
\hline $\mathrm{HDL}-\mathrm{C}(\mathrm{mg} / \mathrm{dL})$ & $31.6 \pm 6.69$ & $29.85 \pm 6.58$ & $29.6 \pm 6.59$ & $37.2 \pm 28.8$ & $35 \pm 20.8$ & 0.122 \\
\hline LDL-C (mg/dL) & $80.55 \pm 21.2$ & $77.65 \pm 15.52$ & $82.7 \pm 17.4$ & $78.6 \pm 14.6$ & $79.2 \pm 15.0$ & 0.398 \\
\hline VLDL-C (mg/dL) & $35.00 \pm 12.21$ & $32.55 \pm 11.47$ & $29.5 \pm 11.7$ & $31.5 \pm 10.78$ & $29.5 \pm 12.2$ & 0.505 \\
\hline $\mathrm{LDH}(\mathrm{mg} / \mathrm{dL})$ & $205.15 \pm 32.7$ & $293.0 \pm 51.61$ & $516.7 \pm 153.7$ & $699.4 \pm 78.6$ & $750 \pm 23.2$ & $0.000^{* *}$ \\
\hline $\mathrm{Ph}$ & $7.03 \pm .035$ & $6.97 \pm 0.04$ & $6.86 \pm 0.07$ & $6.84 \pm 0.15$ & $6.75 \pm 0.04$ & $0.000^{* *}$ \\
\hline Calcium (mg/dL) & $0.04 \pm 0.005$ & $0.045 \pm 0.006$ & $0.048 \pm 0.04$ & $0.05 \pm 0.01$ & $0.05 \pm 0.008$ & $0.011^{*}$ \\
\hline Chloride (mg/dL) & $87.75 \pm 2.55$ & $92.20 \pm 2.41$ & $97.4 \pm 6.62$ & $94.4 \pm 2.45$ & $85.9 \pm 3.30$ & $0.000^{* *}$ \\
\hline Sodium (mEq/L) & $158.8 \pm 2.03$ & $153.2 \pm 2.84$ & $146.7 \pm 6.07$ & $140.2 \pm 4.66$ & $144.75 \pm 4.94$ & $0.000^{* *}$ \\
\hline Potassium (mEq/L) & $3.26 \pm 0.25$ & $6.78 \pm 0.82$ & $10.1 \pm 1.28$ & $16.56 \pm 2.19$ & $20.3 \pm 3.62$ & $0.000^{* *}$ \\
\hline
\end{tabular}




\begin{tabular}{|c|c|c|c|c|c|c|}
\hline $\mathrm{HCO} 3(\mathrm{mg} / \mathrm{dL})$ & $17.6 \pm 1.24$ & $16.78 \pm 1.98$ & $13.09 \pm 2.76$ & $6.25 \pm 3.41$ & $4.79 \pm 1.34$ & $0.000^{* *}$ \\
\hline
\end{tabular}

Table 1: Table showing biochemical parameters at day $0,3,7,14$ and 21 of storage.

\section{Discussion}

Several changes were observed during storage of whole blood in blood bank. Some parameters were found to be decreased while some showed increased values. In some analytes no change was observed. $\mathrm{RBC}$ stored for a period of time at $4^{\circ} \mathrm{C}$ loose viability. Some may undergo spontaneous hemolysis while in storage; others lose the ability to survive in the recipient's circulation following transfusion. Whole blood was stored in CPDA-1 bags. This anticoagulant present in the collection bag is composed of Citrate (chelates ionized calcium that prevents coagulation), Dextrose (a source of energy for the red blood cells), phosphate containing anticoagulants (lower acidity than other anticoagulants without phosphate and have a higher concentration of 2,3 DPG and red cell phosphate) and Adenine (ATP content and posttransfusion viability of red cells regenerated by addition of adenine) [4-6].

Prolonged contact of plasma with RBCs results in exchange of contents between plasma and red cells which leads to changes in analyte concentrations as well as dilution. Potassium levels increased within the period of 3 days and the increase continued subsequently. There was a significant rise in $\mathrm{K}+$ concentration $(\mathrm{p}<0.001)$ from day 1 to day 21 of storage. Latham et al. and Bailey et al. also observed decline in concentration of plasma glucose and bicarbonate and increase in potassium, lactate, $\mathrm{LDH}$, ammonia, and hemoglobin concentration with storage $[7,8]$.

In blood bags the glucose concentration is limited and as glucose is utilized, there is a concomitant ATP (adenosine triphosphate) depletion and decrease in red cell viability [9]. So, energy required for operating ATPase pump in RBCs decreases with time. Under physiological conditions, it pumps three sodium ions out of the cell for every two potassium ions pumped in. Inhibition of sodium pump leads to hyperkalemia and hyponatremia as observed in present study. Adias et al. also observed hyperkalemia in their study but they didn't find any significant change in $\mathrm{Na}+[10]$. Hemolysis also leads to hyperkalemia. During storage there is slow and constant release of potassium ions from cells into surrounding plasma which may be responsible for dramatic increase in potassium in this study. At low temperature there occurs cold-induced blockade of ATP. This leads to extracellular release of $\mathrm{K}+$ and entry of $\mathrm{Na}+$ ions into RBCs $[10,11]$.

Anaerobic glycolysis results in increased concentration of lactic acid which may have caused a decrease in $\mathrm{pH}$ as observed in this study. Significant increase in LDH may also be because of this reason. Hemolysis results in release of $\mathrm{LDH}$ in plasma. LDH best reflects the degree of hemolysis by its increased activity [2]. Castro et al. has also identified total hemoglobin concentration, bilirubin level, lactate dehydrogenase, and the arginine:ornithine ratio to be markers of hemolysis [12].

At 0 day $\mathrm{pH}$ was within normal range which decreased to 6.75 at the end of $21^{\text {st }}$ day. Each 0.1 unit of $\mathrm{pH}$ change results in a $0.4 \mathrm{mmol} / \mathrm{L}$ change in the serum potassium level. Potassium levels are increased by acidosis and decreased by alkalosis [13]. So, this also leads to hyperkalemia. This dramatic increase in potassium levels is dangerous for recipient's body and more dangerous if transfused to a patient with severe kidney disease. This can be prevented by using potassium adsorption filters [11] prior to transfusion or by transfusing blood with $0-3$ day's storage only.

Ionized calcium levels were found to be significantly increased during storage duration from 0 to 21 st day, although the levels were very low (below normal range). This low level of ionized calcium can be explained because of citrate present in CPDA-1 bags, the role of which is to chelate calcium ions to prevent coagulation. Ionized calcium binds to negatively charged sites on protein molecules, competing with hydrogen ions for the same binding sites on albumin and other calcium-binding proteins. This binding is $\mathrm{pH}$ dependent and alters the level of ionized calcium in the blood. Alkalosis, promotes increased protein binding, which decreases free calcium levels. Acidosis, on the other hand, decreases protein binding, resulting in increased free calcium levels [9]. So, increase in levels with storage time may be because of acidosis.

Chloride levels increased initially up to 7 days thereafter a significant decrease was seen. Chloride, calcium and sodium are low molecular compounds and on storage, these enter erythrocytes under the influence of their concentration gradients, namely 19:1 for sodium, 128:1 for calcium and 1.5:1 for chloride resulting in decreased levels in plasma [14]. Phosphorus levels were found to be significantly increased $(\mathrm{p}<0.001)$ with storage duration, from $11.86 \pm 0.62 \mathrm{mg} / \mathrm{dL}$ at 0 day to $16 \pm 0.88 \mathrm{mg} / \mathrm{dL}$ at $21 \mathrm{st}$ day. Whole blood contains many phosphatases which cause hydrolysis of phosphate esters resulting in increase in inorganic phosphate levels [14]. In addition CPDA also has phosphates in it resulting in increased levels [4].

Bicarbonate levels were found to be significantly reduced at the end of study $(\mathrm{p}<0.001)$. This is usually due to buffering of excess lactate production by cells with anaerobic metabolism. Chloride-bicarbonate shift results in inward movement of chloride and outward movement of bicarbonate ions with subsequent buffering of $\mathrm{H}^{+}$ion (from lactic acid) by bicarbonate with production of $\mathrm{CO}_{2}$ gas leading to increased chloride and decreased bicarbonate levels [15]. The blood bags used for storage are made up of polyvinyl chloride (PVC) with plasticizer, di-(2-ethylhexyl) phthalate (DEHP). These bags are easily permeable to $\mathrm{CO}_{2}$. Moderate hemolysis also decreases bicarbonate levels.

Significant changes were observed in AST levels $(\mathrm{p}<0.001)$ which can be because of hemolysis as observed in other studies. Koseoglu et al. studied the effects of hemolysis interferences on routine biochemistry parameters. Hemolysis interference affected LDH and AST almost at undetectable hemolysis by visual inspection (plasma hemoglobin $<0.5 \mathrm{~g} / \mathrm{L}$ ) while clinically meaningful variations of potassium and total bilirubin were observed in moderately hemolyzed samples (hemoglobin >1 g/L). ALT, cholesterol, gamma glutamyltransferase (GGT), and inorganic phosphate concentrations were not interfered up to severely hemolyzed levels (hemoglobin: 2.5-4.5 g/L) [16]. RBCs contain 20 fold as high concentration of AST as 
plasma, so, even mild hemolysis produces significant alterations in AST. We found $51 \%$ increase from day 0 to day 21 in AST levels. The disproportionate correlation with AST, and not ALT, is consistent with higher concentrations of AST than ALT in red blood cells released during intravascular hemolysis [17].

Hemoglobin $(\mathrm{Hb})$ strongly absorbs light at $540 \mathrm{~nm}$. Hemolysis therefore increases absorption in this wavelength range and causes an apparent increase in the concentration of analytes measured in this range. Significant increase in protein concentration is because of addition and optical interference. Additional interference is because of intracellular leakage of total proteins. False elevated protein levels were also observed in study by Roman et al. [18]. Quantitative estimation of total protein was done by biuret method in which absorbance is measured at $546 \mathrm{~nm}$. Hb itself is a protein with same absorbance range [19] but the method was said to be not significantly affected till $\mathrm{Hb}$ concentration of $250 \mathrm{mg} / \mathrm{dL}$ and we did not measure $\mathrm{Hb}$ concentration. So we cannot say whether the increase in total protein was because of addition or optical interference but both can account for this increase.

\section{Conclusion}

Inspite of storing blood with CPDA, the storage time has a negative impact on the biochemical composition of RBCs. Therefore, it is better to give patients fresh blood with less than 7 days of storage in order to decrease the levels of non-viable red blood cells. Further studies are needed to support this evidence.

\section{References}

1. Rudmann SV (2005) Textbook of blood banking and transfusion medicine. Blood component preservation and storage. (2ndedn) 269Elsevier Health Sciences.

2. Frank JJ, Bermes EW, Bickel MJ, Watkins BF (1978) Effect of in vitro hemolysis on chemical values for serum. Clin Chem 24: 1966-1970.

3. Burns ER, Yoshikawa N (2002) Hemolysis in serum samples drawn by emergency department personnel versus laboratory phlebotomists. Lab Med 33: 378-380.

4. AuBuchon JP, Birkmeyer JD, Busch MP (1997) Safety of the blood supply in the United States: opportunities and controversies. Ann Intern Med 127: 904-909.
5. Shields CE (1969) Effect of adenine on stored erythrocytes evaluated by autologous and homologous transfusions. Transfusion 9: 115-119.

6. Monica C (2003) District Laboratory practice in Tropical countries, part 2. Cambridge University Press, Great Britain: 348-361.

7. Latham JT Jr, Bove JR, Weirich FL (1982) Chemical and hematologic changes in stored CPDA-1 blood. Transfusion 22: 158-159.

8. Bailey DN, Bove JR (1975) Chemical and hematological changes in stored CPD blood. Transfusion 15: 244-249.

9. Afri L, Khan AH, Azeem S (2014) Ionized calcium measurement in serum and plasma by ion selective electrodes: comparison of measured and calculated parameters. Indian J Clin Biochem 29: 327-332.

10. Adias TC, Moore-Igwe B, Jeremiah ZA (2012) Storage Related Haematological and Biochemical Changes of CPDA-1 Whole Blood in a Resource Limited Setting. J Blood Disorders Transf 3: 124.

11. Uvizl R, Klementa B, Adamus M, Neiser J (2011) Biochemical changes in the patient's plasma after red blood cell transfusion. Signa Vitae 6: 64-71.

12. Castro O, Hoque M, Brown BD (2003) Pulmonary hypertension in sickle cell disease: cardiac catheterization results and survival. Blood 101: 1257-1261.

13. Hess JR, Sparrow RL, Van der Meer PF, Acker JP, Cardigan RA, et al. (2009) Red blood cell hemolysis during blood bank storage: using national quality management data to answer basic scientific questions. Transfusion 49: 2599-2603.

14. Heins M, Heil W, Withold W (1995) Storage of serum or whole blood samples? Effects of time and temperature on 22 serum analytes. Eur J Clin Chem Clin Biochem 33: 231-238.

15. Boyanton BL Jr, Blick KE (2002) Stability studies of twenty-four analytes in human plasma and serum. Clin Chem 48: 2242-2247.

16. Koseoglu M, Hur A, Atay A, Cuhadar S (2011) Effects of hemolysis interferences on routine biochemistry parameters. Biochem Med (Zagreb) 21: 79-85.

17. Nsiah K, Dzogbefia VP, Ansong D, Akoto AO, Boateng H, et al. (2011) Pattern of AST and ALT changes in relation to hemolysis in sickle cell disease. Clinical Medicine Insights: Blood Disorders 4: 1-9.

18. Roman Y, Bomsel-Demontoy MC, Levrier J, Chaste-Duvernoy D, Jalme MS (2009) Effect of hemolysis on plasma protein levels and plasma electrophoresis in birds. J Wildl Dis 45: 73-80.

19. Pontet F (2000) [Hemolysis and blood proteins]. Ann Biol Clin (Paris) 58 637-638. 